\title{
ON VERTICAL DISTRIBUTION OF MAJOR AEROSOL TYPES OVER DIFFERENT PARTS OF ASIA
}

\author{
Manu Mehta ${ }^{1}$, Narendra Singh ${ }^{2}$, Anshumali $^{3}$, Meghna Mittal $^{4}$, Mahak Gumber ${ }^{4, *}$
}

\begin{abstract}
${ }^{1}$ Photogrammetry \& Remote Sensing Department, Indian Institute of Remote Sensing, Dehradun, India - manu@iirs.gov.in
${ }^{2}$ Aryabhatta Research Institute of Observational Sciences, Nainital, India - narendra5679@gmail.com

${ }^{3}$ Indian Institute of Technology - Indian School of Mines, Dhanbad, India - malijnu@ gmail.com

${ }^{4}$ Banasthali Vidyapith, Tonk, Rajasthan, India - (meghanmittal191997, mehak0197)@ gmail.com
\end{abstract}

Commission V, SS: Atmosphere, Ocean, Weather and Climate

KEY WORDS: CALIOP, dust, polluted dust, smoke, Asia

\begin{abstract}
:
Asia, being the largest continent, both in its size and population is affected by different types of atmospheric aerosols. Also, owing to different local emissions/sources along with the long range transport mechanisms, there is a large variability in the distribution of different types of aerosols across the continent. Not only the effects are pertinent to the regional and global climate system, but the loadings also affect human health. Though there have been studies in the past focussing on columnar distribution of aerosol types over Asian region at continental and regional scales, studies focussed on regional vertical distribution of major aerosol types over different regions of Asia need attention. This paper presents the decadal (2007-16) vertical distribution of major aerosol components, i.e., dust, polluted dust and smoke over different parts of Asia as seen from the space-borne lidar, i.e., Cloud Aerosol Lidar with Orthogonal Polarisation (CALIOP) onboard Cloud-Aerosol Lidar and Infrared Pathfinder Satellite Observations (CALIPSO). Such a study can be useful in capacity building focussed on aerosol variability through remote sensing techniques.
\end{abstract}

\section{INTRODUCTION}

Aerosols are known to have impacts on the Earth's climate system. The spatial distribution of aerosols has helped to understand their contribution to different aspects of climate system as well as human health. However, a comprehensive measurement database of the aerosol vertical structure is still to be established. The knowledge of vertical distribution of aerosols can help to improve the understanding of aerosol induced processes in the atmosphere (Schulz et al., 2006; Winker et al., 2013). One of the major factors behind the diversity in aerosols predicted by modelling approach is the uncertainty in the simulation of transport and removal processes (Huneeus et al., 2011; Kinne et al., 2006; Mehta et al., 2018; Textor et al., 2006).

Though ground based retrievals of aerosol vertical profiles are more accurate but are limited only to point based measurements. In this context, the satellite retrievals can provide continuous mapping of the aerosols though associated with uncertainties. Cloud Aerosol Lidar with Orthogonal Polarisation (CALIOP) is space borne lidar onboard Cloud-Aerosol Lidar and Infrared Pathfinder Satellite Observations (CALIPSO) platform (Hunt et al., 2009; Omar et al., 2009; Winker et al., 2009). It has been providing the vertically resolved aerosol profiles across the globe since 2006.

This work aims to study the decadal variability of aerosol vertical distribution owing to major aerosol types over the three different regions of Asia, dominated by different types of aerosol particles.

\section{STUDY REGION}

We have considered three different regions of Asia i.e., Indonesia (dominated by forest fires and anthropogenic pollution), India (dominated by anthropogenic pollution and natural factors) and Taklimakan Desert (dominated by desert dust). The regions selected for the present study are dominated by different type of aerosols depending on the local sources and long range transport mechanisms.

\section{DATA USED}

The satellite data sets used in the study are taken from CALIOP on board CALIPSO, which orbits around the earth 15 times every day. The lidar signals are received at two wavelengths, i.e., 532 $\mathrm{nm}$ and $1064 \mathrm{~nm}$. Additionally, the lidar is dual polarised at 532 $\mathrm{nm}$. It is capable to retrieve the aerosol and cloud distribution across the globe.

The aerosol retrieval procedure involves identification of aerosol, cloud and surface returns within the lidar signals. Then, the feature type is determined (Liu et al., 2009). The aerosols are classified as clean marine, dust, smoke, polluted dust, clean continental and polluted continental particles (Omar et al., 2009). Finally, the aerosol vertical extinction profiles are retrieved.

For the present study Level 3 monthly datasets at $2^{\circ} \times 5^{\circ}$ spatial resolution have been utilized for the period 2007-2016. Level 3 data products are created using Level 2 datasets using several quality control flags (Winker et al., 2013). In this context, one may refer to evaluation studies by Kim et al. 2013; Kittaka et al. 2011; Ma et al. 2013; Omar et al. 2013. We have analysed the aerosol vertical extinction profiles at $532 \mathrm{~nm}$ wavelength region from the satellite datasets.

\footnotetext{
* Corresponding author
} 
The yearly averages of the monthly vertical profiles have been created followed by the zonal averaging of the datasets for each of the three study regions

\section{RESULTS \& DISCUSSION}

We could obtain the vertical extinction profiles of dust, polluted dust and smoke as major aerosol types from the CALIOP Level 3 datasets.

Figure 1 presents the vertical distribution of these three major aerosol types over India, Indonesia and Taklimakan desert. We observe that overall, the amount of aerosol loading is higher in India compared to that over the other regions under consideration.

Over Indian region, we see that the amount of polluted dust is the dominating aerosol type apart from appreciable concentrations of dust and smoke. The aerosol concentrations for different types remain high up to $2 \mathrm{~km}$ after which the aerosol loadings decrease as we go higher up in the altitudes. Also, the amount of vertical mixing is higher for dust and smoke compared to polluted dust particles. Similar observations were made in another study by Mehta et al., 2018.

Further, considering the Indonesian region, at lower altitude regimes, polluted dust particles dominate, however with rise in altitude, the smoke particle contribution also becomes dominant. Also, important to note here is the fact that the smoke concentrations are maximum within $0.5-2.5 \mathrm{~km}$ amsl (above mean sea level), whereas polluted dust maxima is between $0-1$ $\mathrm{km}$ amsl, after which these decline with altitude.

Over Taklimakan desert, the major aerosol type is dust with large vertical mixing and the particles reach up to $6 \mathrm{~km}$ above mean sea level. The concentrations of polluted dust and smoke are nearly negligible over this region.

The quantitative estimates of vertical distribution of major aerosol types over different regions influenced by local and long range transport sources can provide vital inputs for climate change studies.

Such estimates of vertical aerosol profiles of major aerosol types can be utilized in the studies focussing on aerosol impacts on regional and global climatic conditions.

Further research may focus on the comparative analysis of ground based and space based estimates of aerosol type profiles. Also, a detailed seasonal analysis including special cases of specific aerosol events can also be attempted.
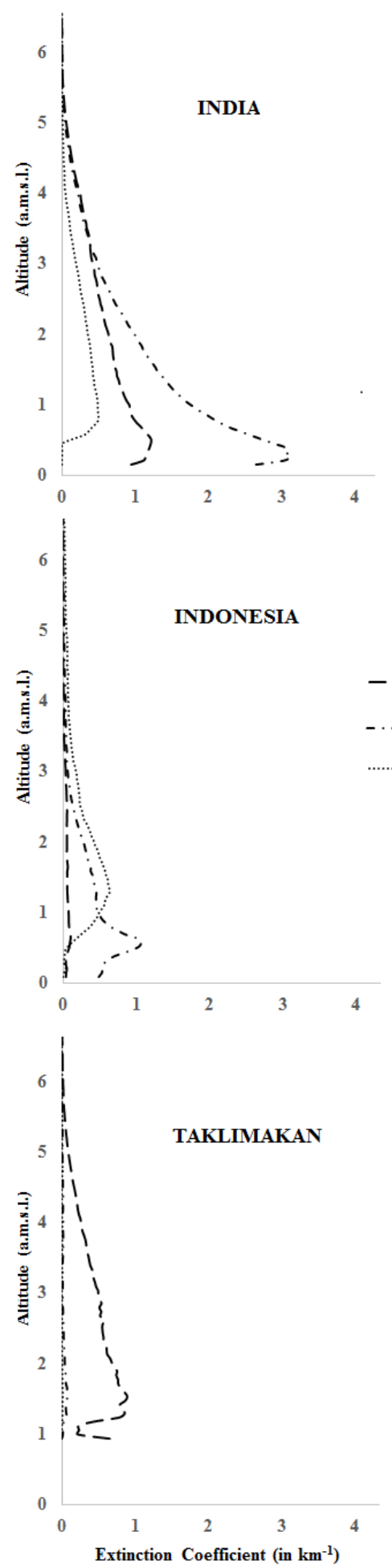

Figure 1 Vertical distribution of dust, polluted dust and smoke over three different regions of Asia

\section{CONCLUSIONS}

The decadal vertical distribution of major aerosol types, i.e., dust, polluted dust and smoke has been studied over the three different regions of Asia with different nature of particle sources.

Following conclusions can be drawn from this study: 
- Over India, all three major aerosol types, namely, dust, polluted dust and smoke are significant contributors to the particle loading. However, polluted dust is the most dominant.

- Over Indonesia, polluted dust and smoke both contribute to the major aerosol types.

- Over Taklimakan desert, dust is the sole aerosol type with strong vertical mixing.

\section{ACKNOWLEDGEMENTS}

We are most thankful to the entire CALIOP team for providing the access to the data.

\section{REFERENCES}

Huneeus, N., Schulz, M., Balkanski, Y., et al., 2011. Global dust model inter comparison in AeroCom phase I. Atmospheric Chemistry Physics, 11, pp. 7781-7816. http://dx.doi.org/10.5194/acp-11-7781-2011.

Hunt, W., Winker, D., Vaughan, M., et al., 2009. CALIPSO Lidar description and performance assessment. Journal of Atmospheric and Oceanic Technology, 26, pp. 1214-1228. http://dx.doi.org/10.1175/2009JTECHA1223.1.

Kim, M. H., Kim, S. W., Yoon, S. C. and Omar, A. H., 2013. Comparison of aerosol optical depth between CALIOP and MODIS-Aqua for CALIOP aerosol subtypes over the ocean. Journal of Geophysical Research - Atmospheres, 118, pp. 13241-13252. http://dx.doi.org/10.1002/ 2013JD019527.

Kinne, S., Schulz, M., Textor, C., et al., 2006. An AeroCom initial assessment - optical properties in aerosol component modules of global models. Atmospheric Chemistry Physics, 6 , pp. 1815-1834. http://dx.doi.org/10.5194/acp-61815-2006.

Kittaka, C., Winker, D.M., Vaughan, M.A., Omar, A., Remer, L.A., 2011. Inter comparison of column aerosol optical depths from CALIPSO and MODIS-Aqua. Atmospheric Measurements Techniques, 4, pp. 131-141. http://dx.doi.org/10.5194/amt-4131-2011.

Liu, Z., Vaughan, M. A., Winker, D. M. et al., 2009. The CALIPSO lidar cloud and aerosol discrimination: version 2 algorithm and initial assessment of performance. Journal of Atmospheric and Oceanic Technology, 26, pp. 1198-1213. http://dx.doi. org/10.1175/2009JTECHA1229.1.

Ma, X., Bartlett, K., Harmon, K. and Yu, F., 2013. Comparison of AOD between CALIPSO and MODIS: significant differences over major dust and biomass burning regions. Atmospheric Measurements Techniques, 6, pp. 2391-2401. http://dx.doi.org/10.5194/amt-6-2391-2013.

Mehta, M., Singh, N and Anshumali, 2018. Global trends of columnar and vertically distributed properties of aerosols with emphasis on dust, polluted dust and smoke - inferences from 10year long CALIOP observations. Remote Sensing of Environment, 208, pp. 120-132, https://doi.org/10.1016/j.rse.2018.02.017.

Omar, A., Winker, D., Kittaka, C. et al., 2009. The CALIPSO automated aerosol classification and lidar ratio selection algorithm. Journal of Atmospheric and Oceanic Technology, 26, pp. 1994-2014. http://dx.doi.org/10.1175/2009JTECHA1231.1.

Omar, A. H., Winker, D. M., Tackett et al., 2013. CALIOP and AERONET aerosol optical depth comparisons: one size fits none. Journal of Geophysica Research - Atmospheres, 118, pp. 47484766. http://dx.doi. org/10.1002/jgrd.50330.

Schulz, M., Textor, C., Kinne, S. et al., 2006. Radiative forcing by aerosols as derived from the AeroCom present-day and preindustrial simulations. Atmospheric Chemistry Physics, 6, pp. 5225-5246. http://dx.doi.org/10.5194/acp-6-5225-2006.

Textor, C., Schulz, M., Guibert, S., KInne, S., Balkansk, Y., Bauer, S., et al., 2006. Analysis and quantification of the diversities of aerosol life cycles within AeroCom. Atmospheric Chemistry Physics, 6, pp. 1777-1813. http://dx.doi.org/10.5194/acp-6-1777-2006.

Winker, D. M., Vaughan, M. A., Omar, A. H., et al., 2009. Overview of the CALIPSO mission and CALIOP data processing algorithms. Journal of Atmospheric and Oceanic Technology, 26, pp. 2310-2323. http://dx.doi.org/10.1175/2009JTECHA1281.1.

Winker, D. M., Tackett, J. L., Getzewich, B. J., Liu, Z., Vaughan, M.A. and Rogers, R.R., 2013. The global 3-D distribution of tropospheric aerosols as characterized by CALIOP. Atmospheric Chemistry Physics, 13, pp. 3345-3361. http://dx.doi.org/10.5194/acp-13-3345-2013. 